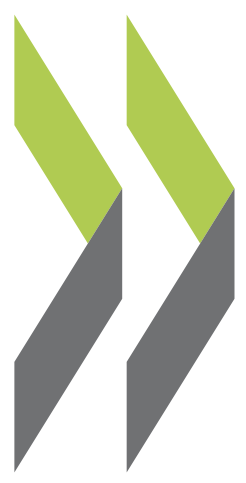

SIGMA Papers No. 15

Checklist on Law Drafting and Regulatory

Management in Central OECD and Eastern Europe 


\section{CHECKLIST ON LAW DRAFTING AND REGULATORY MANAGEMENT IN CENTRAL AND EASTERN EUROPE}

SIGMA PAPERS: No.15 


\section{THE SIGMA PROGRAMME}

SIGMA -- Support for Improvement in Governance and Management in Central and Eastern European Countries -- is a joint initiative of the OECD Centre for Co-operation with the Economies in Transition and the European Union's Phare Programme. The initiative supports public administration reform efforts in thirteen countries in transition, and is financed mostly by Phare.

The Organisation for Economic Co-operation and Development is an intergovernmental organisation of 29 democracies with advanced market economies. The Centre channels the Organisation's advice and assistance over a wide range of economic issues to reforming countries in Central and Eastern Europe and the former Soviet Union. Phare provides grant financing to support its partner countries in Central and Eastern Europe to the stage where they are ready to assume the obligations of membership of the European Union.

Phare and SIGMA serve the same countries: Albania, Bosnia-Herzegovina, Bulgaria, the Czech Republic, Estonia, the Former Yugoslav Republic of Macedonia, Hungary, Latvia, Lithuania, Poland, Romania, Slovakia and Slovenia.

Established in 1992, SIGMA works within the OECD's Public Management Service, which provides information and expert analysis on public management to policy-makers and facilitates contact and exchange of experience amongst public sector managers. SIGMA offers beneficiary countries access to a network of experienced public administrators, comparative information, and technical knowledge connected with the Public Management Service.

SIGMA aims to:

- assist beneficiary countries in their search for good governance to improve administrative efficiency and promote adherence of public sector staff to democratic values, ethics and respect of the rule of law;

- help build up indigenous capacities at the central governmental level to face the challenges of internationalisation and of European Union integration plans; and

- support initiatives of the European Union and other donors to assist beneficiary countries in public administration reform and contribute to co-ordination of donor activities.

Throughout its work, the initiative places a high priority on facilitating co-operation among governments. This practice includes providing logistical support to the formation of networks of public administration practitioners in Central and Eastern Europe, and between these practitioners and their counterparts in other democracies.

SIGMA works in five technical areas: Administrative Reform and National Strategies, Management of Policy-making, Expenditure Management, Management of the Public Service, and Administrative Oversight. In addition, an Information Services Unit disseminates published and on-line materials on public management topics.

Views expressed in this publication do not represent official views of the European Commission, OECD Member countries, or the central and eastern European countries participating in the programme. 


\title{
FOREWORD
}

Central and eastern European countries have to review and adapt their legal frameworks to European Union standards as part of the accession process. This makes the drafting of good quality, "implementable" legislation a major concern.

By publishing this checklist, SIGMA intends to provide a methodological means for evaluating the institutional set-up, procedures and techniques for law drafting adopted in central and eastern European countries, and to identify tools that may be helpful when changes are under consideration. It draws upon practical experiences and practices used in OECD Member countries, as well as in central and eastern European countries. The checklist is not intended as a statement of what must be done, nor a direction as to how particular activities should be treated. Rather, it aims to identify in a quite detailed way a variety of issues which should be considered to ensure good legal quality. Naturally, the actual choices in those respects must reflect local circumstances.

This publication is based on a questionnaire which was prepared for a project launched in 1997 by SIGMA on "Law Drafting and Regulatory Management in Central and Eastern European Countries." This project has led to the publication of a separate SIGMA paper entitled "Law Drafting and Regulatory Management in Central and Eastern Europe" which will also be available through SIGMA. The checklist, written at SIGMA's request by Prof. Keith Patchett of Britain's University of Cardiff, contains questions on policy development, organisational structure, staff, actual drafting and impact assessment. To provide a practical methodological tool, the structure of the checklist tries to reflect as much as possible the development of legal instruments in chronological order.

The checklist aims to assist both staff responsible for reviewing and organising the drafting process and drafting personnel to enhance their awareness of the different aspects of good law drafting. Though the target audience comprises public servants in Central and Eastern Europe, it is not limited to this region as law drafting and regulatory management are under scrutiny in most democracies around the world. Moreover, the checklist may be a useful tool for the donor community.

For more details, including SIGMA activities in this area, please contact Anke Freibert or Michal BenGera at the address below.

A glossary of terms used in the checklist is set out in Annex 1.

\author{
SIGMA-OECD \\ 2, rue André-Pascal \\ 75775 Paris Cedex 16, France \\ Tel (33.1) 45.24.79.00 or 45.24.13.94 \\ Fax (33.1) 45.24.13.00 \\ e-mail: sigma.contact@oecd.org \\ http://www.oecd.org/puma/sigmaweb
}




\section{EXECUTIVE SUMMARY}

The development of a regulatory framework which meets EU standards is a major concern in central and eastern European countries, and this not only to foster economic development but also to ensure the wellbeing of the citizen. To achieve this goal, it is important to create a sound institutional structure, to dispose of staff qualified in law drafting, to set up efficient procedures for co-ordination and consultation, and to ensure that the possible impact of new legal instruments is assessed before they are adopted.

SIGMA has been requested by several of its beneficiary countries to assist them in this extremely difficult task to set up efficient and effective structures and procedures for law drafting. Besides several workshops which have been carried out regarding crucial issues in law drafting, this checklist has been developed to provide countries with an additional means for self assessment.

This checklist offers a means for evaluating structures, procedures and techniques for preparing and drafting legislation, and for identifying methodologies that may be helpful when changes are under consideration. Law drafting comprises two stages: policy development, and preparation of the legislative text to give effect to the policy adopted. The checklist is primarily concerned with the latter.

The checklist draws upon experience gathered in OECD and central and eastern European countries. In particular, it takes into account work carried out by the Regulatory Management and Reform Group of the OECD's Public Management Service (PUMA) and concerns of the EU Phare Programme voiced in the context of the approximation of law with regard to EU accession.

The checklist is designed to provide a practical tool for all those in charge of setting up or revising the drafting process. It therefore covers not only questions concerning the regulation itself, but also organisational and staffing issues.

The organisation of the drafting process, including adequate staffing, is the crucial basis for the production of good legal instruments. In addition, it has proven to be important to undertake a variety of verifications during both the policy development process and the drafting process.

The checklist covers in distinct chapters the following topics:

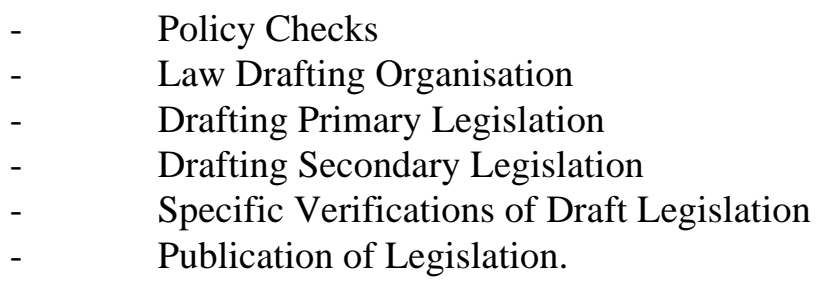

The questions posed under Law Drafting Organisation relate to the regulatory framework, drafting personnel, instruments for verifying drafts, use of computer technology, and consultation procedures. The next two chapters apply to the drafting of primary and secondary legislation, and suggest issues for consideration on procedures, assignment of tasks, timing, and parliament's role in preparing both types of legislation.

To ensure that law drafting yields clear, consistent and enforceable legal instruments, a number of specific verifications are addressed in the corresponding chapter, such as compliance of the legislation and its amendments with the constitution, existing law and legal system, and international obligations. 
Verifications also concern approximation to EU law; implementation; and legal form, clarity, comprehensibility and applicability.

The elaboration of a policy proposal during the drafting process may produce a legislative scheme that covers a wider range of matters, or provides for more complex arrangements than originally foreseen. In such cases, further second-level policy verifications may be warranted once a draft has been prepared.

Checks regarding the sources and publishing of legislation apply to subjects, such as where the text of legislation can be found (e.g. official journal, database), publishing requirements, responsible authorities, access by interested parties, and budgeting. 


\section{TABLE OF CONTENTS}

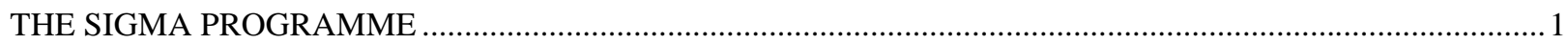

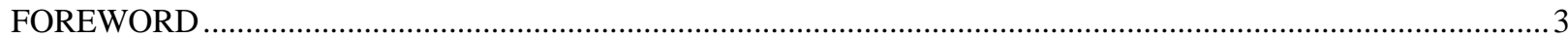

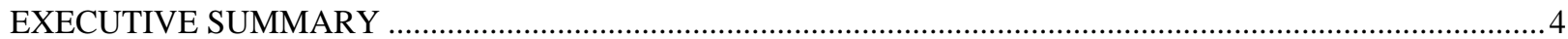

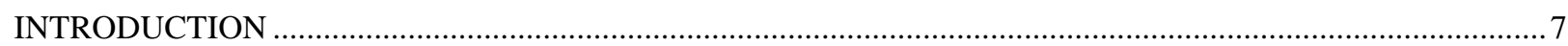

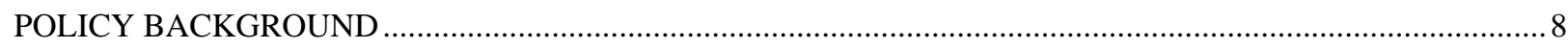

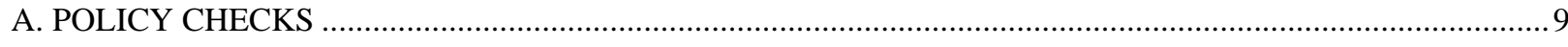

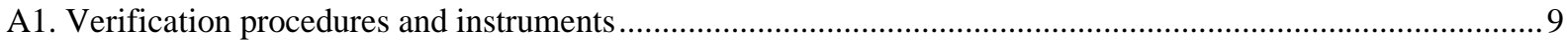

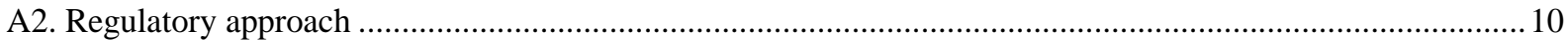

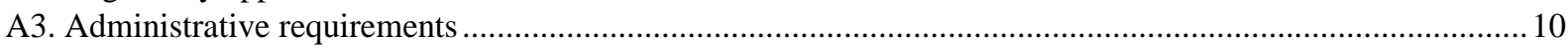

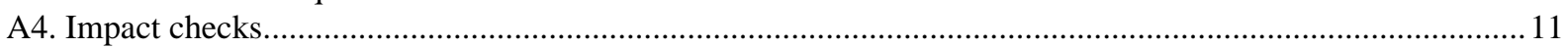

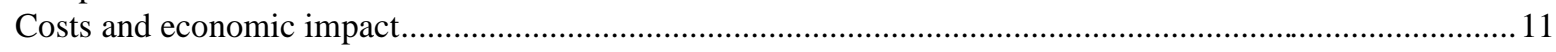

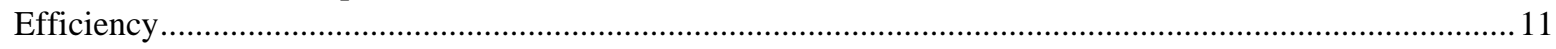

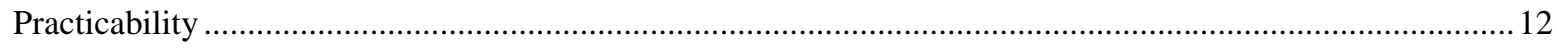

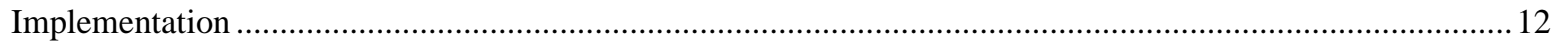

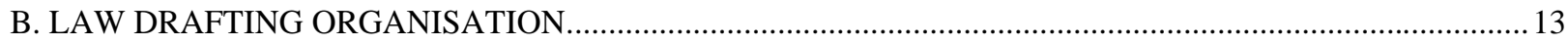

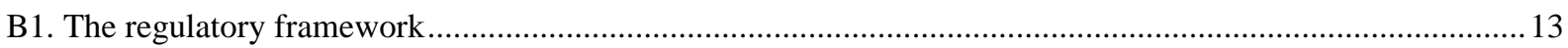

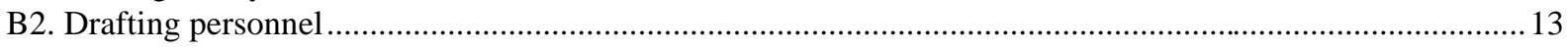

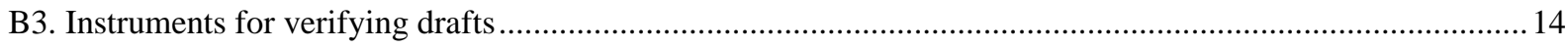

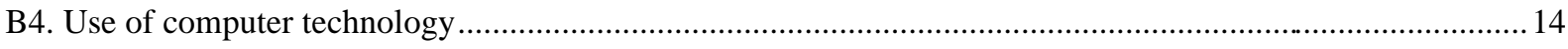

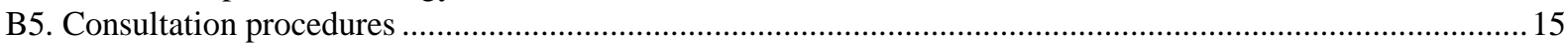





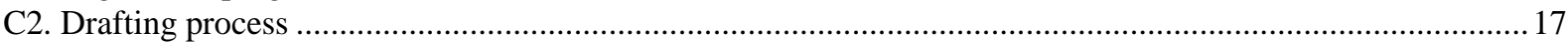

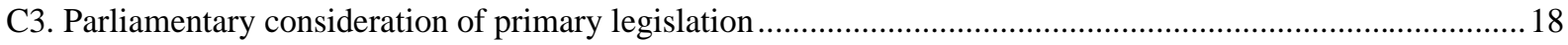

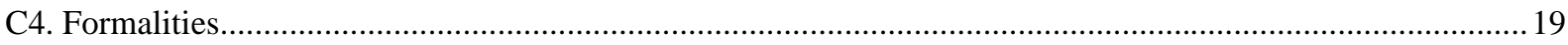

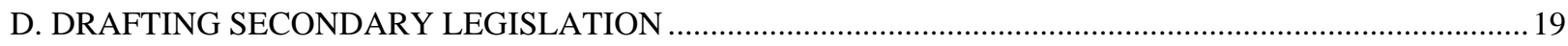

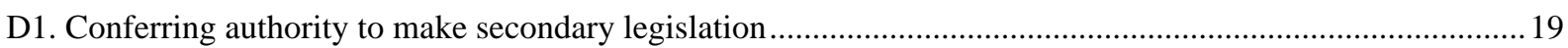

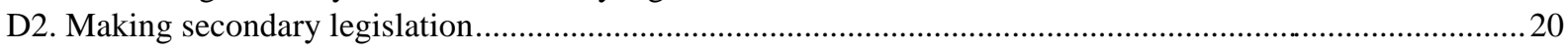



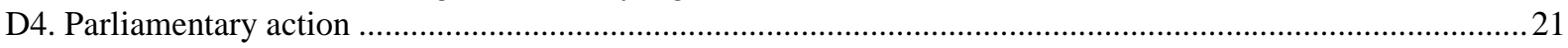



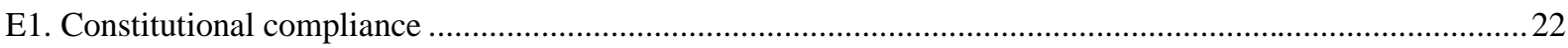

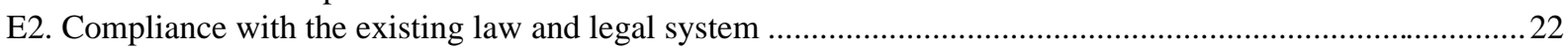

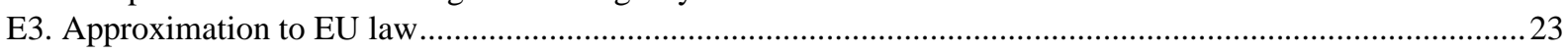

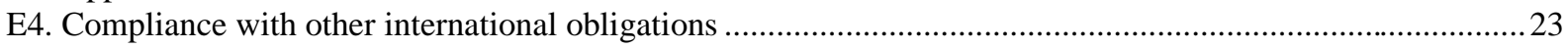

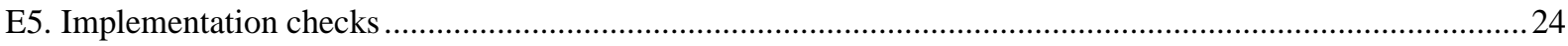

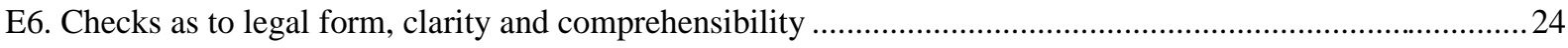

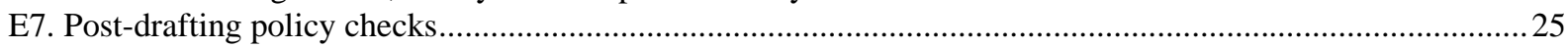

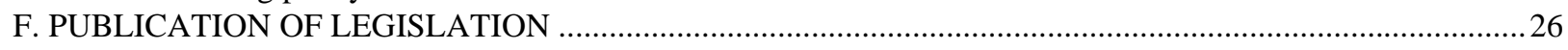

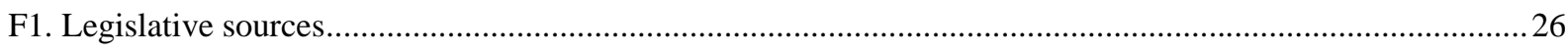

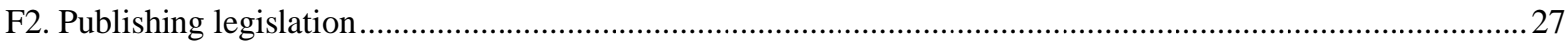

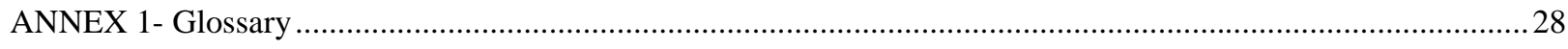

ANNEX 2 - OECD Reference Checklist for Regulatory Decision-Making ....................................................29 


\section{INTRODUCTION}

In principle, law drafting has two stages: policy development and preparation of the legislative text to give effect to the policy adopted. At the first stage, key decisions are needed on such matters as:

- which of the possible policy options is to be preferred;

- whether this option should be realised through legislation, rather than by non-legislative means;

- which authorities should put the legislation into effect; and

- what is the basic approach to be adopted in the legislation, and what legal and administrative mechanisms are necessary to put that approach into effect and make it workable.

Decisions on questions such as these should be provided before effective work can be done on the legislative text. Providing them is properly the task of policy-makers who are expert in the particular subject matter, including those with specialist legal expertise.

At the second stage, these key policy decisions must be converted into legal text, though detailed expert policy and legal inputs on substantive matters will continue to be required. Different, and specialist, legal skills are necessary to turn the policy and administrative requirements into practicable, effective and clear legal rules. Experienced law drafters are well-versed in how to use the appropriate legal concepts and terminology in legislative contexts, and how to give effect to the prevailing drafting conventions as to legislative structure, form and style.

In some systems, these two stages may be kept formally separate, but in most central and eastern European countries they are likely to be dealt with by the same ministry officials or working group.

Although this checklist is primarily concerned with the second of the two stages, the first section outlines the kinds of checks that are valuable in policy development. In many countries law drafters are asked to prepare explanatory documentation in support of the legislation they have drafted ("justifications"), in which information on the policy background must be included. 


\section{POLICY BACKGROUND}

OECD Member countries have found that the quality of their legislation can be greatly enhanced if certain issues are specifically addressed. On 9 March 1995, the OECD Council recommended that the following questions always be asked when regulatory action is under consideration:

1. Is the problem correctly defined?

2. Is government action justified?

3. Is regulation the best form of government action?

4. Is there a legal basis for regulation?

5. What is the appropriate level (or levels) of government for this action?

6. Do the benefits of regulation justify the costs?

7. Is the distribution of effects across society transparent?

8. Is the regulation clear, consistent, comprehensible, and accessible to users?

9. Have all interested parties had the opportunity to present their views?

10. How will compliance be achieved?

The full Recommendation is set out in Annex 2.

It is evident that most are key policy questions that should properly be settled before any legislation is prepared (e.g. 1-6, 10), and may need to be asked with respect to each of the possible policy options in order to determine which is to be preferred. On the other hand, question 8 can only be considered when the legislation is drafted. In some cases, the question can be asked at either stage (e.g. 7 \& 9). Furthermore, a question, although considered at the policy-making stage, may sometimes have to be asked again at the drafting stage as the detailed scheme in the text emerges.

The answers to all these questions, no matter how and when they are obtained, are important for the work of the law drafter. Indeed, if they are not provided in the course of the policy development, law drafters may have to ask for them or attempt to provide them themselves in the course of drafting. 


\section{A. POLICY CHECKS}

OECD Member countries use the following verifications as part of an ex ante assessment of legislative projects, to improve the reliability, effectiveness and cost efficiency of the law. When relevant, they should be applied by each body responsible for initiating legislation - both primary and, though usually to a lesser extent, secondary legislation. They should be built into the standard drafting processes used within government and, in respect of legislation and amendments to legislation initiated there, by parliament too.

These questions do not focus on the means by which particular verifications can best be carried out (e.g. whether by a central expert body acting for all ministries or by specialist units within individual ministries), or whether they should be dealt with in a single exercise. That necessarily depends upon the availability and local organisation of specialist resources.

\section{A1. Verification procedures and instruments}

A1.1 Do regulations identify the persons or bodies responsible for carrying out the following verifications, in particular when they are to be conducted centrally or by individual ministries and when the work may be contracted out, e.g. to external agencies or consultants?

A1.2 Has consideration been given to establishing a single government unit which can develop the special competence required?

A1.3 Do regulations give guidance as to the stage of the drafting process at which these verifications are to be carried out (e.g. when the policy options are considered, or when a particular option has been selected, or when the law draft has been completed, or at more than one of these stages)?

A1.4 Do they prescribe the procedures to be followed, especially in those cases where problems are found in relation to the project proposals?

A1.5 Do regulations stipulate that the justifications submitted with drafts of legislation to the council of ministers and parliament must include a formal notification that these verifications have been carried out and, in particular, information on projected costs, financial impact and budgetary implications?

A1.6 Have formal arrangements been instituted to ensure that similar checks are carried out in relation to legislative drafts or amendments initiated by parliament?

A1.7 Are formal instruments in use or under development to assist in the ex ante assessment of policy proposals for legislation (e.g. computer models, simulations, checklists)?

A1.8 Has any governmental body or bodies been made responsible for researching the experience of other countries in the use of ex ante assessment, for developing suitable instruments for local use, and for ensuring that their existence is made known to those who might use them?

A1.9 Is government providing opportunities for training, in-country or abroad, in the use of formal ex ante assessment? 


\section{A2. Regulatory approach}

A2.1 Are procedures in place to ensure that the problem to be solved can be precisely and correctly identified, its nature and scale fully explored, and its cause thoroughly understood by the policymakers, and that the policy objectives can be firmly established?

A2.2 Is it standard practice for ministries to undertake an initial analysis and verification of alternative policy options in order to determine how the policy objectives are to be secured?

A2.3 Is it standard procedure for a specific check to be made as to whether new legislation is required at all, e.g. because the matter:

a) is or can be dealt with under existing law, or

b) can be dealt with or without legislative action (e.g. by administrative directives, such as contract or negotiation and agreement with affected parties)?

A2.4 Are the policy proposals and the policy options for new legislation specifically verified, during the policy-making stages, for compliance with the requirements of the constitution?

A2.5 Are the policy proposals and the policy options for new legislation specifically verified, during the policy-making stages, for compliance with existing law and legal structures?

\section{A3. Administrative requirements}

A3.1 Is it standard practice to establish, in relation to each new legislative project, the most appropriate level in government at which the new scheme should be implemented?

A3.2 Is it standard practice to carry out a check in relation to each new legislative project to establish:

a) that the organisational structures and administrative procedures necessary to make a new scheme fully operational already exist and will be adequate for the purpose, or

b) if they do not exist or are considered to be inadequate, that the additional requirements needed can be provided to the level necessary for effective implementation?

A3.3 Is it standard practice to carry out a check in relation to each new legislative project to establish:

a) that adequate resources, particularly human resources, already exist to make a new scheme fully operational, or

b) if they do not, the resources that will need to be provided?

A3.4 In the course of this verification, is specific attention required to be paid to whether, and in what ways, computer-assisted administration could be used in the implementation process?

A3.5 If so, is it standard practice to check the impact upon implementation of using computer systems (e.g. in terms of increased, or saving of, costs or of likely delays to the commencement of the scheme until the computer systems, and the consequential training, have been completed)? 


\section{A4. Impact checks}

\section{Costs and economic impact}

A4.1 Have regulations been made to direct the use of cost verification in relation to new legislative projects?

A4.2 Do the regulations stipulate the types of legislative projects for which a cost assessment is appropriate, and in particular indicating the cases where it must be used?

A4.3 Have formal procedures been instituted for assessing the impact on the government's budget of new legislative projects, in terms of both capital and recurring costs and, in particular, personnel and organisational costs?

A4.4 Have formal procedures been instituted for assessing the impact on the budgets of other governmental authorities (such as local government or provincial authorities) of new legislative projects?

A4.5 Do the regulations require that cost assessments include an assessment of the:

a) financial impact on private sector bodies likely to be affected by new legislative projects, particularly in terms of greater administration costs and capital expenditure, and

b) indirect financial impact of new legislation on the private sector, e.g. on investment strategies and possible reductions in tax payments?

A4.6 Do the regulations:

a) require that cost assessments include an assessment of the impact of the proposed scheme in terms of increased social costs in the general community;

b) give guidance as to the criteria to be applied to determine whether such increases will be acceptable, or e.g. merely lead to unintended changes in public behaviour; and

c) require that an assessment be made of the likely short-, medium- or long-term consequences of new legislation for employment?

A4.7 Have procedures been instituted to enable government to find out by ex post evaluation whether projected costings were realistic?

\section{Efficiency}

A4.8 Do regulations require checks to be carried out specifically to assess whether a proposed legislative scheme will achieve its objectives?

A4.9 In particular, is this verification designed to check:

a) that the scheme will achieve its objectives at the minimum cost, and

b) whether it may lead to counterproductive effects or unintended and inappropriate consequences? 
A4.10 Does this verification include the preparation of a statement of the expected benefits of the new legislation (including relevant quantitative data), in particular indicating the shortcomings of the existing law and how the new scheme will help to improve the situation?

\section{Practicability}

A4.11 Are checks required to be carried out specifically to assess whether a proposed legislative scheme will actually:

a) provide the intended benefits for those who are intended to benefit, and

b) meet the operational needs of the administration that is to execute it?

A4.12 Does this verification include an examination of whether the scheme will lead public administration to establishing unnecessary or excessive bureaucracy or to applying unnecessarily complex administrative procedures?

A4.13 Does this verification include an examination of whether administration of the scheme will overburden the private sector in terms of unnecessary or unduly complex procedures (e.g. to obtain official authorisation) or elaborate compliance arrangements?

A4.14 Does this verification include an assessment of whether the scheme will make demands upon public administration or the private sector that will not be cost-effective, i.e. in economic terms, demands which will be disproportionate to the benefits that will ensue?

A4.15 Does this verification include an assessment of the likely impact of the scheme, both on those to whom it is principally directed and indirectly on third parties, in terms of additional expense or restrictions or loss of benefits or of personal or economic opportunities?

A4.16 Does this verification include an examination of whether the scheme could lead to opportunities for corrupt practices in its administration (e.g. illegal payments to officials to obtain licences)?

A4.17 Does this verification include an assessment of the likelihood of public acceptance of the scheme once operational and of the likely public response or reaction in terms of changes in behaviour (both intended and unintended)?

\section{Implementation}

A4.18 Does specific consideration need to be given to the methods by which compliance with the legislation will be secured and to determining the:

a) legal provisions that will be required to ensure the effective implementation of the legislative scheme, and

b) human, institutional and financial resources that will be needed to give effect to the selected method of enforcement?

A4.19 Does a specific check have to be carried out to assess whether the proposed methods for securing compliance, for the enforcement of the legislative scheme, and for adjudicating disputes, will be effective, fair, consistent and open in their operation? 
A4.20 Does a specific check have to be carried out to determine that the compliance, enforcement and adjudication methods proposed are likely to command the confidence and co-operation of those affected and are within their capacity of compliance?

\section{B. LAW DRAFTING ORGANISATION}

\section{B1. The regulatory framework}

B1.1 Are there regulations stipulating the procedures and requirements to be followed in drafting legislation? Have they been revised since the transition?

B1.2 Are these regulations gathered together in a single regulatory instrument (i.e. legislation, directive or handbook) that is used by all legislative drafters?

B1.3 Do these regulations prescribe standard procedures that are to be followed in the drafting process and standard requirements as to form, format, style of drafting, and operation of legislation?

B1.4 Is any governmental body (e.g. a minister) responsible for formulating and updating these procedures and requirements, and for ensuring that common standards set by them are followed by the law drafters in individual ministries?

B1.5 Are regulatory checklists used for these purposes, or being developed?

B1.6 Is any parliamentary or judicial body specifically charged with verifying that the standards are consistently followed in the drafting of legislation?

B1.7 Is a single governmental body (e.g. a senior minister) specifically charged with the oversight of the regulatory framework and/or with co-ordinating the programme of drafting activities being undertaken by ministries?

\section{B2. Drafting personnel}

B2.1 Is law drafting recognised as an expert legal skill that every ministry needs from time to time and that calls for specialist qualities best acquired through systematic training and actual experience?

B2.2 Does each governmental body that is responsible for preparing legislation (e.g. ministry) have, or have access to, a sufficient number of experienced law drafters to meet its needs?

B2.3 Does parliament have, or have access to, a sufficient number of experienced law drafters to meet its law drafting needs, or those of its commissions or members, in initiating draft legislation or in preparing amendments to government bills?

B2.4 Would the resourcing of drafting be made easier if ministry budgets were to provide specific funds for the employment of law drafters?

B2.5 Are steps being taken to ensure that those engaged in law drafting have the appropriate level of experience and training to undertake the particular tasks assigned to them? 
B2.6 Would there be advantage if, in the terms and conditions of government service, specific recognition were given to the specialist skills and expertise required of law drafters? In particular, are there opportunities for law drafters to receive promotion or other advancement in that capacity?

B2.7 Is the drafting competence of officials engaged in law drafting formally and periodically assessed (e.g. by performance appraisal)?

B2.8 Do all those who may be expected to undertake law drafting receive basic training in the specialist skills needed for law drafting?

B2.9 Is training made available to allow law drafters to upgrade their skills from time to time?

B2.10 Are there arrangements to enable those new to law drafting, or with limited experience, to work with or under the supervision of officers more experienced in law drafting?

B2.11 Is there a uniform policy as to when consultants or other experts from outside government service may be employed to prepare drafts of legislation? Are the cost-benefits of using such persons rather than ministry drafters regularly evaluated?

B2.12 Are steps taken to ensure that such consultants or experts are competent law drafters and knowledgeable in the prevailing requirements and standards for the preparation of legislation?

B2.13 Is the quality of the work of law drafters (whether in a ministry or external) monitored by a senior official in the ministry? In particular, are the individual drafts specifically verified for drafting faults before the ministry treats them as completed?

B2.14 Are ministry drafters made available to parliamentary or similar commissions to explain or clarify legislation with which the drafters have been concerned? Is their availability sufficiently publicised to those bodies?

\section{B3. Instruments for verifying drafts}

B3.1 Are formal instruments in use or being developed to assist in the assessment of the drafts of legislation (e.g. checklists relating to subject content or quality standards)?

B3.2 Is any governmental body responsible for researching the experience of other countries in the systematic use of drafting checks and for developing suitable instruments for local use?

B3.3 In particular, is use made or under consideration of modelling, algorithms, flow-charts, or critical path analyses in the preparation of legislation?

B3.4 Are there formal guidelines as to the use of legislation from other countries either as a model for policy makers or as a legislative precedent for law drafters?

\section{B4. Use of computer technology}

B4.1 Is it government policy to make full use of computer technology in the drafting process? 
B4.2 Is every law drafter supplied with a personal computer for his/her own exclusive use so that drafts can be composed directly on computers?

B4.3 Do all law drafters use the same word-processing package? Is this a standard application or are steps being taken to develop one specifically for use in law drafting?

B4.4 Is an official, computerised database of legislation in use or being developed to which law drafters can have on-line access for purposes of searching for laws affected by the changes or for precedents?

B4.5 In the absence of an official database, do law drafters have on-line access to a database of the legislation relating to their ministry's responsibilities?

B4.6 Does the government printer use modern, computerised publishing equipment?

B4.7 Is it technically possible for law drafters to provide the government printer with the text of legislation they have drafted in a form (e.g. on diskette or on-line) that enables the legislation to be printed without further typesetting?

\section{B5. Consultation procedures}

B5.1 Have regulations been made that stipulate:

a) the standard procedures by which consultations with affected persons are to be carried out, the information to be given to those persons and how, and within what timescale their responses are to be made and considered;

b) how such consultations are to be made effective, fair and open; and

c) how compliance with consultation procedures is to be monitored and, in cases where they are mandatory, enforced?

B5.2 Have formal arrangements been made to afford opportunities to the general public to comment upon legislative proposals or draft legislation, in particular stipulating how the attention of the public is to be drawn to legislative proposals and how their responses are to be sought, made and considered?

B5.3 Is use made of advisory groups, whether permanent or temporary, to assist in the development of new law on specific subjects?

B5.4 Have formal arrangements been made to enable consultation procedures to be followed in respect of legislation initiated by parliament?

B5.5 Do regulations stipulate that the justifications submitted to the council of ministers and parliament must include a statement as to the bodies that have been consulted during the drafting process? 


\section{DRAFTING PRIMARY LEGISLATION}

\section{C1. Legislative programme and timetables}

C1.1 Does government (e.g. through the council of ministers) agree a formal programme of bills that are to be prepared for consideration in forthcoming sessions of parliament?

C1.2 Does the government have a formal procedure (e.g. consideration by a committee of the council of ministers) for deciding, from the competing claims of ministries, to which legislative projects priority should be given in the next legislative programme?

C1.3 Does government stipulate an annual timetable for determining legislative priorities and for agreeing the next legislative programme?

C1.4 Does the legislative programme establish government's legislative priorities for forthcoming parliamentary sessions, that will be deviated from only in emergencies?

C1.5 Does this programme cover a sufficiently long period (e.g. at least a year) to enable the concerned ministries to plan the drafting of their legislation effectively?

C1.6 Does government collectively (e.g. by the council of ministers) approve or confirm the policy objectives of each new legislative project before the drafting process is permitted to begin?

C1.7 Is an overall timetable set for the preparation of the bills in the legislative programme? Is its implementation centrally co-ordinated and compliance centrally monitored?

C1.8 Is each bill drafted in a ministry formally approved by the relevant minister on completion of the drafting?

C1.9 Has each completed bill to be submitted to, and agreed to collectively by government (e.g. the council of ministers) before it may be introduced into the parliament?

C1.10 Is a comparison formally made (e.g. by a committee of the council of ministers) between the policy objectives as initially approved and the final legislative draft, to determine that both are consistent, before the draft is approved by government?

C1.11 Is every bill submitted to the council of ministers accompanied by detailed explanatory material (e.g. a justification) describing the legislative objectives and the mechanisms employed and indicating the verifications that have been carried out (see sections A \& E of this checklist) and their results?

C1.12 Is the timing of the introduction of a bill into the parliament decided upon collectively by government (e.g. by the council of ministers)?

C1.13 Does government give parliament sufficient notice of the introduction of particular bills to enable parliament to programme its legislative activities effectively?

C1.14 Are the persons responsible for introducing the bill into the parliament on behalf of government, and for its presentation and defence there, provided with a full brief on the legislative objectives and scheme? 
C1.15 Are there adequate arrangements to enable the law drafters concerned with a bill to provide necessary briefings on drafting considerations to those persons both before and during its parliamentary consideration?

\section{C2. Drafting process}

C2.1 Are there clearly defined arrangements within ministries for selecting and assigning the law drafters who are to be responsible for drafting the ministry's bills?

C2.2 In preparing a bill dealing with a wide-ranging or complex matter, is it the practice to involve officials with special competence in the subject matter as well as officials specialising in law drafting (e.g. by establishing a "bill team" or working group within the responsible ministry or by some other means)?

C2.3 Are there clear guidelines (including directions as to permitted expenditure) to indicate when individual ministries may involve persons from outside the ministry, and particularly from outside government, in the work of a bill team?

C2.4 Is a timetable set in the ministry for the completion of each bill? In particular, is consideration given to the time needed for preparing, considering and consulting on the number of drafts that are likely to be required for the particular legislation?

C2.5 Is it standard practice for a bill team to work out the objectives, methodology and scheme of new legislation, and in particular to solve potential operational problems, before systematic work is undertaken on drafting the text of the bill?

C2.6 Once the objectives, methodology and scheme have been settled, is the law drafter given full responsibility for preparing the text of the draft bill, for consideration by the bill team or by ministry officials?

C2.7 Are there clear guidelines (including directions as to permitted expenditure) to indicate when, at what stages and by what means, the bill team may or must consult other ministries on the contents of legislation?

C2.8 Are there clear guidelines as to when, and from whom, comments may or must be sought from interest groups or experts outside government, on the various drafts of a bill? Do these guidelines require a time frame to be set within which requested comments are to be made?

C2.9 In particular, are there clear guidelines as to the circumstances in which the text of a draft bill is to be treated as confidential to government, and as to who can authorise persons outside government to comment upon a draft before its introduction into parliament, and under what conditions?

C2.10 Have standard directions been issued as to who is responsible for scrutinising the text of legislative drafts for errors of content or presentation or printing? For example, is it clear who is responsible for proof-reading all versions of the bill, including that finally agreed to by parliament? 
C2.11 Is there any procedure by which parliament or political groups in parliament can consider and comment upon (a) the policy and legislative scheme of a proposed bill and/or (b)the form, structure or drafting of the bill itself before it is formally introduced into the parliament?

\section{C3. Parliamentary consideration of primary legislation}

C3.1 Is adequate time afforded to members of parliament to study the contents of a bill and to consult interested parties before its first substantive parliamentary consideration? In particular, do the rules of procedure in parliament make provision in this respect?

C3.2 Is adequate explanatory information (e.g. justification) provided with a bill on its introduction into parliament? Are there standard guidelines as to what this must contain and who is responsible for preparing it?

C3.3 Are such justifications published or available to members of the public (either for studying the bill or when the legislation is in force)?

C3.4 Is legal advice and assistance available to members of parliament (e.g. from its secretariat) to enable them to examine a bill in parliament effectively, and particularly on the existing content and shortcomings of the law which the bill seeks to reform or to amend?

C3.5 Do the rules of procedure in parliament enable parliament to take evidence from ministry officials, external experts or informed members of the public when considering a bill?

C3.6 Is drafting assistance and advice available to members of parliament (e.g. from its secretariat) to support them in drafting amendments or bills of their own for introduction in parliament?

C3.7 When amendments to government bills are proposed by parliament, are there adequate arrangements to ensure that the amendments are drafted consistently with the objectives and language of the bill?

C3.8 Do the rules of procedure in parliament stipulate time limits by which amendments to government bills must be notified before their consideration in parliament? Are these sufficient to enable government, as well as members of parliament, to look into the implications of an amendment?

C3.9 Do the rules of procedure afford government adequate opportunities to examine bills and amendments introduced by members of parliament and to report its views formally to parliament?

C3.10 If parliament introduces a bill of its own, are there any formal processes to ensure that parliament, in preparing the bill, is made aware of, e.g. financial and operational constraints on government which any legislative action must take into account?

C3.11 Are there any formal mechanisms whereby bills or amendments initiated by parliament can be subjected to impact verifications similar to those that were applied by government to the original bill?

C3.12 Is it standard practice for officials of the drafting ministry (in particular, law drafters) to monitor the progress of their bill in parliament? 
C3.13 If government concludes that a bill, or a parliamentary amendment, currently before parliament needs to be altered, do the rules of procedure in parliament enable the drafting ministry to put forward its own amendment?

\section{C4. Formalities}

C4.1 Do bills that alter existing legislation expressly identify the precise places where the legislation is amended, and do they specify precisely the terms of the alteration? In particular, are amendments to legislation made in the form of specific changes or additions to, or deletions from, the text of that legislation?

C4.2 Are there standard rules prescribing how legislative provisions that have financial implications (e.g. for expenditure or taxing) are to be dealt with?

C4.3 Are there standard legal rules prescribing when legislation comes into force, if not expressly provided for in the legislation itself?

C4.4 Are there standard legal rules regulating the use of government orders for the purpose of bringing legislation into force and the modes by which such a power may be exercised?

C4.5 Do standard legal rules prescribe that legislation automatically expires if not brought into force within a specified time?

\section{DRAFTING SECONDARY LEGISLATION}

\section{D1. Conferring authority to make secondary legislation}

D1.1 Are there recognised purposes or matters for which secondary legislation should be used or should not be used to implement primary legislation? In particular, do regulations stipulate that matters that are likely to have a significant or controversial policy content should be dealt with by primary legislation?

D1.2 When secondary legislation is needed to implement primary legislation, is it standard practice to confer the power to make it, and to stipulate the body on which it is conferred, in the primary legislation?

D1.3 Does the general law set limits or conditions governing the exercise by governmental bodies of their powers to make secondary legislation?

D1.4 Is it standard practice for the primary legislation to impose specific limits upon the exercise of the secondary law-making power (e.g. by confining its use to specifically stated purposes)? In particular, does the primary legislation typically stipulate mandatory procedures to be complied with when the secondary legislation is made (e.g. with respect to consultation)?

D1.5 Is it standard practice during the drafting of the primary legislation to check that sufficient legal authority has been provided to enable all the secondary legislation to be made that is likely to be needed? 
D1.6 Are checks carried out during the drafting of the primary legislation to determine that the delegation of power to make secondary legislation is constitutional?

D1.7 Where primary legislation must be implemented by secondary legislation in order to make a legislative scheme effective, are checks carried out to ensure that the primary legislation will not come into force before all the secondary legislation required has been drafted?

\section{D2. Making secondary legislation}

D2.1 Do regulations stipulate the persons who decide that secondary legislation has to be prepared for the purpose of implementing particular primary legislation, who direct the formal steps that have to be followed when secondary legislation is being made, and who determine whether any cases require the collective consent of government?

D2.2 Are the same officials within a ministry that had developed the policy for the primary legislation typically directed to determine the contents of the secondary legislation? Is a law drafter involved at this stage?

D2.3 Is the drafting of secondary legislation within a ministry typically undertaken by a law drafter? Are steps taken to enable the work to be done, if possible, by the law drafter who drafted the primary legislation?

D2.4 Do regulations stipulate other government bodies (within the relevant ministry or within other ministries) which must be included in discussion of the secondary legislation?

D2.5 Is any requirement set by regulations with respect to consultation with affected parties or special interest groups?

D2.6 Do regulations stipulate the stage of the law making when internal and public consultations are to take place and how they are to be conducted?

D2.7 In particular, is consideration given to whether specific secondary legislation of importance to the public should be published, before it is formally made, for public comment within a set time frame?

D2.8 Do regulations stipulate formal requirements that law drafters must observe when drafting secondary legislation, in particular requiring checks to be made to determine the:

a) necessary legal authority exists to make the requested secondary legislation;

b) contents of the proposed legislation are consistent with the primary legislation which it implements; and

c) secondary legislation does not conflict with other law?

D2.9 Do regulations set out the conventions, particularly as to form and style, which law drafters are expected to comply with when drafting secondary legislation?

D2.10 Do regulations stipulate the circumstances when secondary legislation must be submitted for the approval of the council of ministers and the supporting documentation provided? 
D2.11 Do regulations stipulate the formal action by which a draft instrument becomes effective law (e.g. signature of a minister, followed by publication in the Official/National Gazette)?

\section{D3. Procedures after the making of secondary legislation}

D3.1 Is any body (either collectively for government or within individual ministries) given responsibility for carrying out a final check, after secondary legislation is made, with respect to validity or form, and for prescribing the body's powers, especially in relation to defective instruments?

D3.2 Is there any legal requirement that all secondary legislation is to be registered centrally, and that stipulates how the register is to be maintained, and by whom, and the details that must be registered?

D3.3 Is any governmental body charged with compiling and publishing an official index or other similar guide to all secondary legislation that has been made and is in force, as it relates to specific primary legislation?

D3.4 Do regulations prescribe how soon after being made secondary legislation has to be published?

D3.5 Is there a legal requirement that, with specified exceptions, secondary legislation must first be published in order to be effective law? If not, are restrictions imposed by law on the use of secondary legislation before it is published?

\section{D4. Parliamentary action}

D4.1 Do regulations stipulate that specified secondary legislation is to be sent or reported to parliament (e.g. because of its policy content or controversial nature) and how, and within what time limits, such communications are to be made?

D4.2 Are there standard requirements as to when secondary legislation must be confirmed or may be disapproved by parliament?

D4.3 Do the rules of procedure in parliament provide for examination, or debate, of secondary legislation on parliament's initiative?

D4.4 Has parliament power to amend secondary legislation made by government? Do the rules of procedure provide for the way in which such amendments are to be put forward and considered, and do they allow opportunities for government responses?

D4.5 If parliament has power to initiate secondary legislation, are the instruments prepared by experienced law drafters?

D4.6 Is there a procedure under which instruments initiated by parliament must be submitted to the relevant ministry for comment before parliamentary approval is given? Is there a procedure to ensure that the cost and economic impact of the legislation are fully considered in the drafting process? 
D4.7 Has parliament established a committee to keep under review the way in which secondary lawmaking powers are exercised? Do the rules of procedure confer effective powers on that body?

\section{E. SPECIFIC VERIFICATIONS OF DRAFT LEGISLATION}

The following verifications are used in OECD Member countries, in the course of drafting legislation, to improve its quality as a legal instrument that contains clear, consistent, comprehensible and enforceable law. They should be applied by everyone responsible for drafting legislation - both primary and secondary. Accordingly, they should be standard features of the drafting process within government and within parliament too, in respect of legislation and amendments to legislation initiated there.

\section{E1. Constitutional compliance}

E1.1 Are the texts of the various drafts of legislation (primary or secondary) specifically verified, during the drafting stages, for compliance with the requirements of the constitution?

E1.2 In particular, is compliance with particular constitutional provisions (e.g. those relating to human rights or citizens' rights) specifically verified?

E1.3 Has parliament instituted formal arrangements to verify that legislative drafts or amendments proposed by them comply with the requirements of the constitution?

E1.4 Do regulations stipulate how and to whom the fact and results of this verification must be notified and the consequential action that may be taken where difficulties are found?

\section{E2. Compliance with the existing law and legal system}

E2.1 Is a specific check made, before drafting begins, to confirm that new legislation is required and that the matter cannot be dealt with under existing law or by other means not requiring legislation?

E2.2 Is the text of each draft of particular legislation (whether primary or secondary) specifically verified by the law drafters during the drafting stage for consistency with existing law, legal structures and procedures?

E2.3 Have formal arrangements been made for verifying that the:

a) law draft conforms to existing legal requirements that prescribe environmental standards, and

b) implementation of proposed legislation will meet existing national standards relating to protection of the environment?

E2.4 Do regulations stipulate that specific investigations are to be made by the law drafters, at the conclusion of the drafting of new legislation, to ascertain and make legislative provision for:

a) all provisions of existing law that must be repealed or amended, and 
b) transitional provisions that need to be included, in order to ensure legal continuity between the new legislation and the existing law?

\section{E3. Approximation to EU law}

E3.1 Has a specific methodology been designed for checking the consistency of existing or new legislation with EU law?

E3.2 Do regulations prescribe the types of legislation (in the hierarchy of legislative instruments) that are to be subject to this verification and the criteria to be applied when compliance with EU law is checked?

E3.3 Do regulations clearly identify the body or bodies that are responsible for filtering out the drafts which are to be subjected to the check and for applying the criteria to those drafts?

E3.4 Do regulations prescribe the procedure to be followed if legislation is considered not to comply with some aspect of EU law? Do they identify the authority which is to make the final decision on action to be taken with respect to draft legislation that is incompatible with applicable EU law?

E3.5 Do regulations stipulate that all draft legislation forwarded to the council of ministers must be accompanied by a statement attesting to the fact that the verification has been carried out for this purpose and setting out the extent to which the legislation complies with EU law (e.g. a certificate of compliance)?

E3.6 Have formal arrangements been instituted to ensure that legislative drafts or amendments proposed by parliament are verified for compliance with EU law?

\section{E4. Compliance with other international obligations}

E4.1 Have formal arrangements been instituted specifically for verifying that draft legislation is consistent with the European Convention on Human Rights?

E4.2 Have formal arrangements been instituted for verifying that draft legislation is consistent with other treaty obligations already, or likely to be, entered into, which may impact upon the particular matter covered by the legislation (e.g. treaties relating to environmental matters, ILO Conventions)?

E4.3 Do regulations identify the persons or bodies responsible for carrying out this verification? Do they prescribe the procedures to be followed, in particular in cases where inconsistencies have appeared?

E4.4 Do regulations stipulate that all draft legislation forwarded to the council of ministers must be accompanied by a statement that the verification has been carried out for this purpose and that the legislation complies with treaty law?

E4.5 Have formal arrangements been instituted to ensure that legislative drafts or amendments initiated by parliament are verified for compliance with treaty law? 


\section{E5. Implementation checks}

E5.1 Do law drafters carry out a systematic check to determine that the draft legislation contains all the legal provisions required to enable the scheme to be fully implemented and its administration to be made fully operational?

E5.2 Is specific consideration given to the methods by which compliance with the new legislation will be secured and to determining the legal provisions that are necessary to ensure the effective implementation of the legislative scheme?

E5.3 Does a specific check have to be carried out to assess whether the proposed methods for securing compliance, for the enforcement of the legislative scheme, and for adjudicating disputes, will be effective, fair, consistent and open in their operation?

E5.4 Does a specific check have to be carried out to determine that the compliance, enforcement and adjudication methods adopted are likely to command the confidence and co-operation of those affected and are within their capacity of compliance?

E5.5 Are law drafters required to check specifically that the legislative language used facilitates the functioning of courts in adjudicating issues, and in the settlement of disputes, arising under the legislative scheme?

E5.6 Does a specific check have to be carried out to determine the human, institutional and financial resources that will be required to implement the draft, and the extent to which resources may need to be improved, and how this will be achieved?

E5.7 Have formal arrangements been made to ensure that this verification is also carried out in respect of legislation initiated by parliament or of amendments to legislation, whether initiated by government or by parliament?

E5.8 Do regulations stipulate that the justifications submitted to the council of ministers and parliament must include a formal notification that this verification has been carried out?

\section{E6. Checks as to legal form, clarity and comprehensibility}

E6.1 Do regulations stipulate the standard forms that law drafters are expected to follow in drafting legislation, in particular with respect to the:

a) form of primary and secondary legislative instruments (e.g. provision of a title, and mode of numbering instruments and of dividing and numbering internal divisions);

b) opening and closing formulae and technical provisions dealing with the objectives, operation and application;

c) positioning of particular types of legislative provisions (e.g. those relating to enforcement, repeal or amendment of other legislation, transitional provisions);

d) forms to be used for particular types of legislative provisions (e.g. penal provisions, amending and repealing provisions); and

e) layout and printing styles? 
E6.2 Do regulations stipulate standard drafting practices to be followed in composing the text of legislation (e.g. legislative structure, style of writing, terminology, definitions, internal consistency and avoidance of ambiguity)?

E6.3 Have formal arrangements been made to ensure that law drafters, both in government and serving parliament, adopt the same standard forms and follow the same standard drafting practices?

E6.4 Has government instituted a formal policy that legislation must:

a) be drafted in such a way as to be easy to understand and work with;

b) be clear in the way its contents are set out;

c) avoid unnecessarily legalistic terms; and

d) be written in language of standard usage by the public affected by the legislation?

E6.5 Have formal arrangements been made to carry out a systematic verification that all new legislation meets these standards?

E6.6 Are law drafters encouraged to agree on drafting conventions that are specifically designed to give effect to these objectives?

E6.7 Has any body been given responsibility for determining how the quality of law drafting may be improved, in particular in language and style, in order to make legislation more accessible?

\section{E7. Post-drafting policy checks}

The elaboration of a policy proposal during the drafting process may produce a legislative scheme that covers a wider range of matters, or provides for more complex arrangements, than initially envisaged. In those circumstances, further, second-level policy verifications may be appropriate after a draft is completed. Those verifications may also be needed for the purposes of completing the justification that typically accompanies primary legislation.

In particular, such checks are likely to be concerned again with matters considered earlier under he following headings in this checklist:

1. administrative requirements: A3.2-3

2. cost and economic impact: $A 4.3-5$

3. efficiency: $A 4.9$

4. practicability: A4.11-16

5. implementation: A4.19-20.

E7.1 Do regulations stipulate when completed drafts of legislation (e.g. drafts that are likely to have significant social or economic effects) are to be subjected to fresh policy verifications before so adoption by the council of ministers and submission to the parliament?

E7.2 Are procedures in place to refer these drafts to the appropriate body conducting the verifications so that their conclusions can be taken into account by the law drafter when revising the draft? 


\section{F. PUBLICATION OF LEGISLATION}

\section{F1. Legislative sources}

F1.1 Is there an official journal (e.g. Official/National Gazette) in which the authentic official texts of legislation, including bills, are published?

F1.2 Do regulations require all legislation, primary and secondary, to be published in this journal immediately after it is made?

F1.3 Do regulations stipulate that all primary legislation and secondary legislation must be republished in annual volumes?

F1.4 Has a central registry, or a registration system, been established for registering all primary and secondary legislation to permit a complete archive to be created and maintained?

F1.5 If an electronic database of legislation is provided by government, or is under consideration:

a) have steps been taken to ensure that it contains legislation in a form that can guaranteed by the state as authentic, and

b) will lawyers, judges, and the public be permitted to have on-line access, as well as government officials?

F1.6 Do regulations require that a consolidation of primary and secondary legislation (containing all the law in force on the date of publication) is to be prepared and published at regular intervals?

F1.7 Are there arrangements by which any legislation that has been substantially amended can be reprinted in a consolidated form that is authentic?

F1.8 Is there a requirement to publish, at regular intervals, an official, up-to-date index of the legislation currently in force that indicates also where, when and how earlier legislation has been amended?

F1.9 Is every ministry required to maintain a complete collection of current legislation relating to matters within its competence?

F1.10 Does every ministry have ready access to a complete collection of all legislation in force? In particular, do all law drafters typically have access to a full set of legislation?

F1.11 Are complete collections of current legislation kept in centres to which members of the legal profession and the public have ready access? Are sufficient funds made available to enable these collections generally to be well maintained?

F1.12 Can lawyers and enterprises in the private sector easily acquire an authentic and complete set of legislation in force? Are copies of individual instrument readily available throughout the country, at a price that members of the public can afford?

F1.13 Has government established, or charged, any body or bodies with the responsibility of: 
a) keeping the state of the current legislation under review (e.g. with a view to bringing forward proposals for repealing legislation that is obsolete or no longer effective), and

b) preparing and publishing, at regular intervals, consolidations of the primary and/or secondary legislation currently in force?

\section{F2. Publishing legislation}

F2.1 Do regulations stipulate a timescale for printing bills after approval by government or initiation by members of parliament and prior to being introduced into parliament?

F2.2 Do the regulations stipulate the stage in the drafting process at which a bill is to be published, when it is to be made available to the public (e.g. for purchase) and to whom copies are to be automatically supplied gratis?

F2.3 Do regulations indicate from whose budgets (e.g. government collectively, individual ministries, parliament) the costs of printing and publishing legislation are to be met?

F2.4 Do regulations make clear who has the authority to make changes to the text of legislation after it is made, but before final publication, and in what circumstances (e.g. to correct printing errors)?

F2.5 Do regulations stipulate how soon legislation is to be officially published after it is made or enacted, and any exceptional circumstances in which it may come into force before it is published? 


\begin{abstract}
ANNEX 1- Glossary
amending legislation: legislation that alters the effect of existing legislation, whether by modifying or repealing provisions or by adding or substituting new provisions

approximation of law: the process of bringing the contents of existing legislation into harmony with the requirements of EU law
\end{abstract}

bill: the draft of primary legislation in the form that will be considered by parliament

consolidation: the process of producing a comprehensive and coherent collection of legislation, or of legislative rules, on a specific subject, in an organised format

ex ante assessment: the process of assessing qualitatively a feature of proposed legislation before a final decision is made to adopt it

law drafter: a person (whether a government official or a contracted consultant) engaged in producing the text of new legislation

law drafting: the process of converting new policy into legal rules in legislation, in the appropriate legal form and style, prior to the act of law-making

legislation: written law made by parliament, the government or other body vested with power (usually by the constitution) to issue law-making instruments

primary legislation: legislation made by parliament (i.e. the body vested with the principal law-making function for the state)

regulatory framework: the standard arrangements (as dictated by law) for preparing legislation, including any legal requirements as to the standard procedures to be followed and as to the form and style in which legislation is to be drafted

regulation: any of the range of legal instruments that may be made by parliament, the government or the public administration to influence behaviour (i.e. law-making instruments, such as primary and secondary legislation, and non-law-making instruments, such as circulars, directions, guidance or instructions)

regulatory management: the systematic management of the processes of developing, drafting and making new legislation

secondary legislation: normative instruments (e.g. decrees, directives, regulations, rules, orders) made by government or another executive body vested with power to issue such instruments in order to implement secondary legislation

verification: a process for scrutinising a policy proposal or draft legislation in order to check that it meets some specific standard or required quality 


\title{
ANNEX 2 - OECD Reference Checklist for Regulatory Decision-Making
}

\author{
Recommendation of the Council of the OECD, adopted 9 March 1995
}

The following ten questions about regulatory decisions reflect principles of good decision-making that are in use in OECD Member countries to improve the effectiveness and efficiency of government regulation by upgrading the legal and factual basis for regulations, clarifying options, assisting officials in reaching better decisions, establishing more orderly and predictable decision processes, identifying existing regulations that are outdated or unnecessary, and making government actions more transparent. But they have to be applied within a broader regulatory management system that includes elements such as information collection and analysis, consultation processes, and systematic evaluation of existing regulations.

1. Is the problem correctly defined?

The problem to be solved should be precisely stated, giving clear evidence of its nature and magnitude, and explaining why it has arisen (identifying the incentives of affected entities).

2. Is government action justified?

Government intervention should be based on clear evidence that government action is justified, given the nature of the problem, the likely benefits and costs of action (based on a realistic assessment of government effectiveness), and alternative mechanisms for addressing the problem.

3. Is regulation the best form of government action?

Regulators should carry out, early in the regulatory process, an informed comparison of a variety of regulatory and non-regulatory policy instruments, considering relevant issues such as costs, benefits, distributional effects, and administrative requirements.

4. Is there a legal basis for regulation?

Regulatory processes should be structured so that all regulatory decisions rigorously respect the "rule of law"; that is, responsibility should be explicit for ensuring that all regulations are authorised by higherlevel regulations and consistent with treaty obligations, and comply with relevant legal principles such as certainty, proportionality, and applicable procedural requirements.

5. What is the appropriate level (or levels) of government for this action?

Regulators should choose the most appropriate level of government to take action, or, if multiple levels are involved, should design effective systems of coordination between levels of government.

6. Do the benefits of regulation justify the costs?

Regulators should estimate the total expected costs and benefits of each regulatory proposal and of feasible alternatives, and should make the estimates available in accessible format to decision-makers. The costs of government action should be justified by its benefits before action is taken. 
7. Is the distribution of effects across society transparent?

To the extent that distributive and equity values are affected by government intervention, regulators should make transparent the distribution of regulatory costs and benefits across social groups.

8. Is the regulation clear, consistent, comprehensible, and accessible to users?

Regulators should assess whether rules will be understood by likely users, and to that end should take steps to ensure that the text and structure of rules are as clear as possible.

9. Have all interested parties had the opportunity to present their views?

Regulations should be developed in an open and transparent fashion, with appropriate procedures for effective and timely input from interested parties such as affected businesses and trade unions, other interest groups, or other levels of government.

10. How will compliance be achieved?

Regulators should assess the incentives and institutions through which the regulation will take effect, and should design responsive implementation strategies that make the best use of them. 